\title{
Improving the management of a highly inbred species: the case of the White-winged Wood Duck Cairina scutulata in captivity
}

\author{
CYNTHIA TOMLINSON, GEORGINA \\ M. MACE, JEFFREY M. BLACK and \\ NIGEL HEWSTON
}

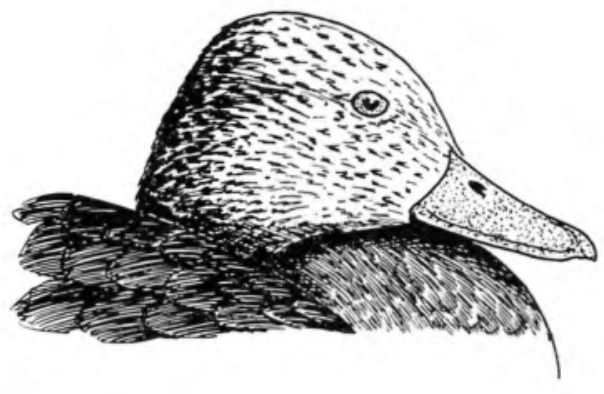

Studbook data on captive White-winged Wood Duck were analysed to help in the forward planning of an ongoing breeding programme. Conservative assumptions were made to fill gaps in the data set and enable analyses. The population growth rate seems to have declined since 1985, but this is due at least in part to deliberate management decisions and to missing data. The present population of 70 individuais is descended from just seven founders with a founder genome equivalent score of 2.58 . This score could be improved only slightly by breeding to equalise the genetic contributions of individual founders. The data were analysed to assess the minimum viable population size required to maintain a population with $90 \%$ heterozygosity retained for 200 years. A realistic minimum population size of 500 to 600 could achieve this goal only with an increase in the number of founders to between ten and 20 , and an increase in the ratio of effective to census population size. The planned establishment of an international studbook will improve the data available and may lead to more optimistic analyses.

The White-winged Wood Duck Cairina scutulata of southeast Asia has been the subject of various conservation measures since 1968 (Mackenzie \& Kear 1976). In 1921 the birds were described as common throughout southeast Asia (Baker 1921), but in 1959, Delacour (1959) described them as not rare, but never numerous. The duck is now extinct in Malaysia and on Java (Green in press). The remaining isolated flocks are seriously threatened due to exploitation of the tropical forests on which they depend (Kear \& Williams 1978, Collar \& Andrew 1988, Green 1990, in press).

In 1969 and 1970, 12 wild birds were collected as eggs and ducklings in Assam and brought to the Wildfowl Trust, Slimbridge, to establish a captive population. The fate of these birds has been closely monitored (Mackenzie \& Kear 1976). A studbook maintained at Slimbridge for the British population also contains some data on captive birds in Asia and the USA, and The Smithsonian Institution, Washington, DC, holds some studbook data for US birds.

In order for captive populations to provide an effective insurance against the extinction of a species and to make a significant contribution to the conservation of species, they must be managed along sound biological principles to be genetically diverse and demographically viable (Foose 1983). In this paper we examine the genetic and demographic status of the popula- tion from the studbook data, and make some recommendations for future management. As a guide to improving the genetic variation in the captive population of White-winged Wood Duck, we attempt to assess the minimum viable population size (MVP) (i.e. the number of individuals which needs to be maintained to provide for genetic and demographic viability). An MVP depends upon several interacting factors including the overall objectives of the captive breeding programme - especially the time scale and genetic and demographic goals, the biological characteristics of the species and the resources that are available (Foose 1983, Foose et al. 1986, Soule et al. 1986, Foose \& Ballou 1988).

\section{Methods \\ Goals and objectives}

Basic demographic and genetic objectives for the captive breeding programme were considered first. While an ideal breeding programme would aim to maintain all genetic variability for ever, this is an impossibility in real situations. One commonly adopted aim for captive breeding programmes is to maintain $90 \%$ of starting genetic heterozygosity for a period of 200 years (Soule et al. 1986). The 90\% criterion has been arbitrarily chosen to represent a compromise 
between a "potentially damaging and a tolerable loss of heterozygosity" (Soule et al. 1986). The 200 years criterion is likewise a compromise between short-term programmes (accepting a rate of inbreeding of $1 \%$ per generation but assuming that reintroduction to the wild will be realized within 100 years) and longer time frames which for many species would monopolize a larger proportion of zoo resources than managers are prepared to accept for a single species. Both these criteria were chosen as initial guidelines and can be changed to suit the species and the circumstances.

The population size (or MVP) necessary to achieve this goal will depend upon a number of factors. Of particular importance are the generation length characteristic of the population, the number of founders (unrelated wild-caught individuals ancestral to the living population), the population growth rate and the genetically effective population size of the population. This last variable incorporates the actual breeding patterns of the population and gives an estimate of the number of breeding individuals in an ideal population (with equal sex ratios, non-overlapping generations, constant population size, equal number of offspring from different parents, random mating and no heritability of fertility) which would have similar genetic characteristics to the population being studied (Harris \& Allendorf 1989). If the population does not have all these ideal characteristics, the genetically effective population size will then be smaller than the actual census size, and may often be of the order of only $20-40 \%$ of the census population. For example if only a fraction of the adults produce offspring which themselves breed, then only this fraction of the population contributes genes to the next generation. The studbook data were therefore analysed to estimate these values.

\section{Studbook data}

Studbook data from the Wildfowl \& Wetlands Trust records, comprising birth and death dates, the parentage and the location of each individual were entered into the SPARKS studbook management package (ISIS 1989). The total studbook included 454 individuals in 41 locations and covered the period between 1969 and 1989. Of all the birds listed eight were recorded as wild bom and the rest captive bom.

Only those birds known to be alive on 31 December 1989 were used in the analyses concerning the living population, while birds for which no recent information was available were assumed to have died $(\mathrm{N}=83,18 \%)$. This conservative assumption may have had confounding effects on the analyses and these are presented in the discussion.

Similarly, conservative but realistic assumptions were made when assigning parents to those individuals that had unidentified, but captive parents. Twenty birds ( $4 \%$ ) were hatched where two or three adult males and/or females were kept together, and in each case the most prolific of the possible parents were assumed to be the real parents. In the case of 69 other hatchlings (15\%) no possible parents were listed, but by considering their year and location of birth it was possible to make realistic assumptions, always assigning the most prolific breeders of that or the previous year as parents.

With these assumptions, the demographic and genetic analyses which follow present a worst case scenario, for there are certainly more individuals alive, and genetic variability may be greater, than found here. It is likely to be less damaging to make overly conservative assumptions.

\section{Genetic analyses}

The pedigree recorded in the studbook was analysed to examine the number of wild founders, the extent of inbreeding and the effect of inbreeding on survival and fecundity. Simulation analyses based on the methods of MacLuer et al. (1986) were also used to estimate founder number and the extent to which founder genetic diversity was preserved in the living population. In these techniques, often referred to as 'gene drop' methods, two unique hypothetical alleles are allocated to each founder at the head of a pedigree. Using a random number generator, and following the rules of Mendelian inheritance, a genotype is then created for each descendant. The set of alleles surviving in the living individuals is then recorded and over the course of a large set of similar runs ( 5000 simulations), counts of allele survival from different founder individuals are made for individual living animals as well as for the living population as a whole. From these values estimates can be made of the amount of genetic variability retained. The methods for summarising these data, and for utilising them in breeding programmes are discussed by MacLuer et al. (1986) and Lacy (1989). Estimates were also made of the genetically effective size $\left(N_{k}\right)$ of the living population according to analytical methods presented by Hill (1972), Reed et al. (1986) and Harris \& Allendorf (1989). These values were compared with an estimate based on the 
overall heterozygosity preserved in the gene drop simulations according to the equality:

$$
\mathrm{H}=1-\frac{1}{2 \mathrm{~N}_{\mathrm{e}}}
$$

where $\mathrm{H}$ is the proportion of heterozygosity retained (Crow \& Kimura 1970). The latter method makes fewer assumptions about the way that breeding success is distributed among individuals than the analytical methods, but has the disadvantage that it relies on complete knowledge of the pedigree.

\section{Demography}

The basic demographic analysis was as described by Foose \& Ballou (1988). Essentially a life table with age- and sex-specific rates of survival and fecundity was constructed from the studbook data and used to calculate generation length and population growth rate. Because this species has quite a long captive history, and the number of breeding pairs and their breeding patterns have varied widely, the basic demographic statistics were calculated separately for the three time periods 1968 to 1979,1980 to 1984 and 1985 to 1990 . For making predictions
Table 1. Studbook population of White-winged Wood Ducks at 31 December 1989.

\begin{tabular}{lrcc}
\hline Collection & \multicolumn{3}{c}{ Number of birds } \\
& male & female & unknown \\
\hline Slimbridge & 16 & 9 & 0 \\
Martin Mere & 8 & 9 & 0 \\
Washington & 2 & 1 & 0 \\
Peakirk & 4 & 3 & 0 \\
Chester Zoo & 2 & 2 & 0 \\
Jersey Zoo & 2 & 2 & 0 \\
Harewood & 2 & 1 & 0 \\
Harrison & 1 & 1 & 0 \\
Child Beale Trust & 1 & 1 & 0 \\
National Zoological Park & & & \\
$\quad$ (USA) & 1 & 1 & 0 \\
Lubbock (USA) & 0 & 1 & 0 \\
& 39 & 31 & 0 \\
\hline
\end{tabular}

the later data (1985 to 1990) were used since these were thought most likely to be characteristic of present populations.

\section{Calculation of MVP}

An algorithm developed by J. Ballou (National Zoological Park) was used to calculate the MVP required to maintain $90 \%$ heterozygosity for time periods from 50 to 200 years, based on the

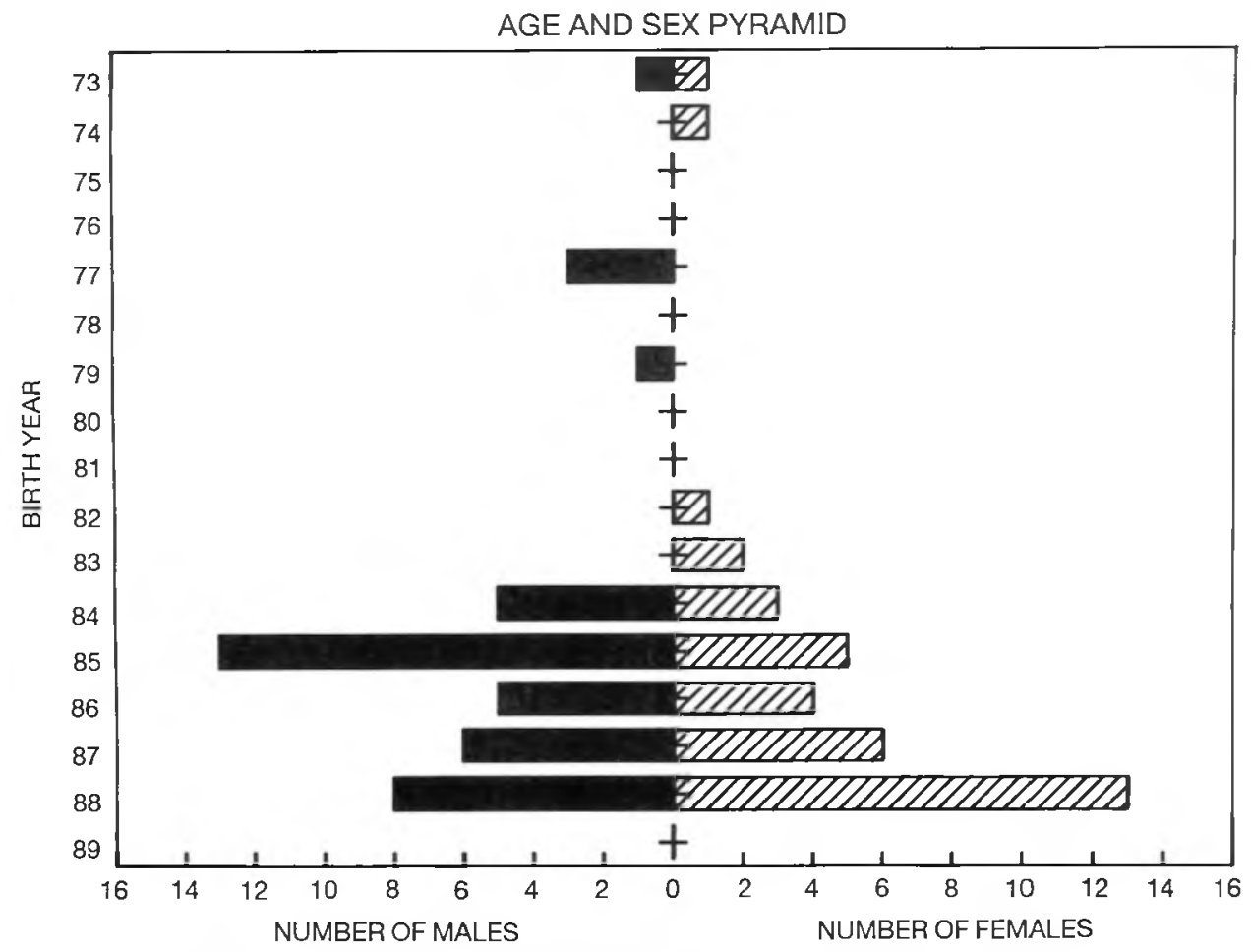

Figure 1. Age and sex structure of the known population of White-winged Wood Ducks on 31 December 1989. 
Table 2. Average generation length ( $t$ ), growth rate (lambda), longevity (long.), age and maximum longevity (max. long.) for three time periods since 1968 for both males (M) and females (F).

\begin{tabular}{|c|c|c|c|c|c|c|}
\hline & \multicolumn{2}{|c|}{$1968-79$} & \multicolumn{2}{|c|}{$1980-84$} & \multicolumn{2}{|c|}{$1985-90$} \\
\hline & $\mathbf{M}$ & $\mathrm{F}$ & $\mathbf{M}$ & $\mathrm{F}$ & $\mathbf{M}$ & $\mathbf{F}$ \\
\hline $\mathrm{t}$ & 4.08 & 3.16 & 3.38 & 3.49 & 4.36 & 4.15 \\
\hline lambda & 1.13 & 0.97 & 1.15 & 1.15 & 1.07 & 1.04 \\
\hline long. & 5.7 & 5.0 & 5.0 & 5.0 & 5.6 & 6.3 \\
\hline age & 3.2 & 2.9 & 3.7 & 3.5 & 3.5 & 3.2 \\
\hline max. long. & 12 & 12 & 13 & 14 & 17 & 17 \\
\hline
\end{tabular}

discussions of Soule et al. (1986). This method calculates loss of genetic diversity (heterozygosity) by genetic drift in a population that grows from the founder number to MVP at a specified growth rate (lambda), where throughout the growth phase the effective population size, generation length and population growth rate are constant, and as measured in the analyses described above.

\section{Results}

\section{Population status}

The recorded population at the end of 1989 consisted of 70 individuals ( 39 males and 31 females) distributed among 11 institutions (Table 1).

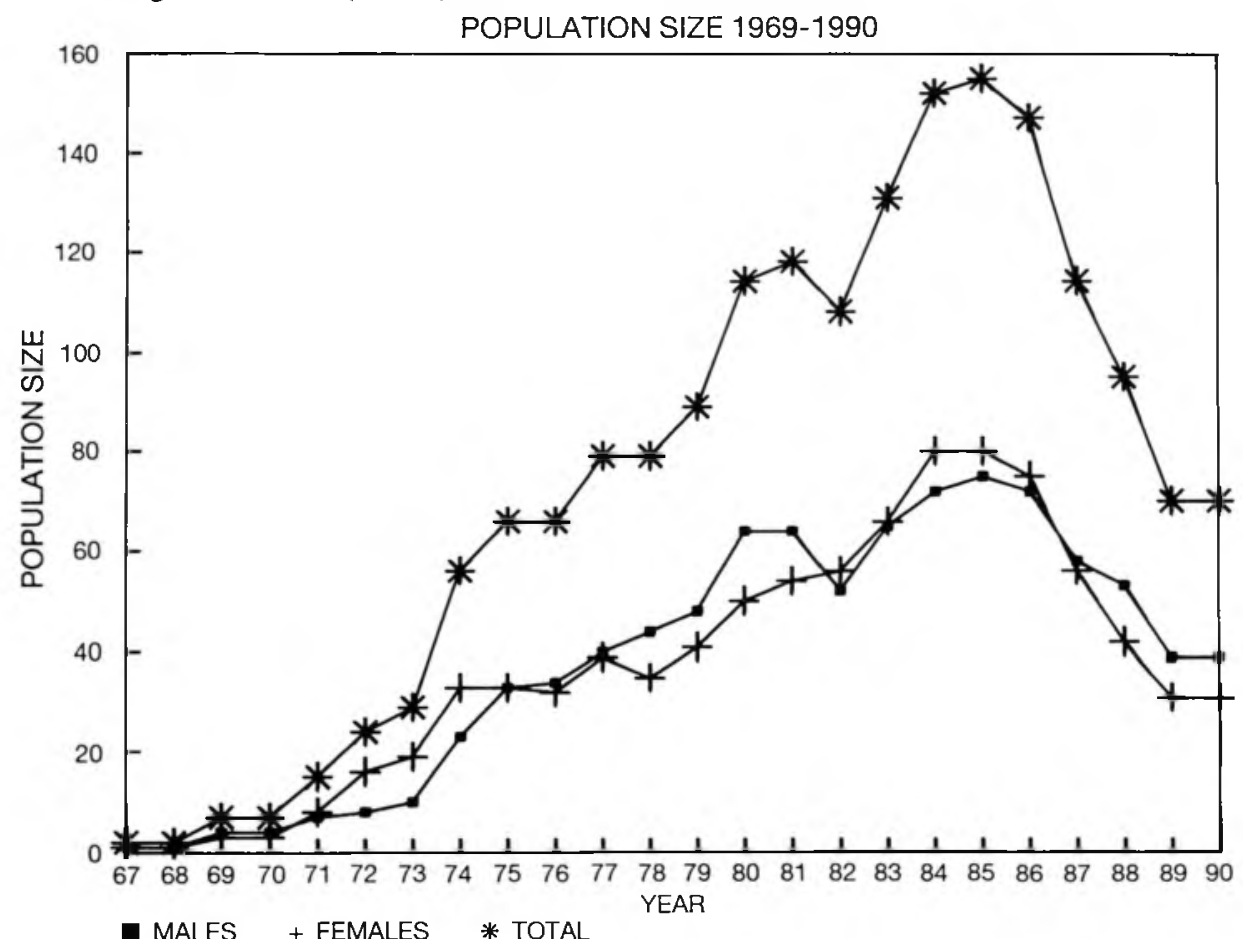

Figure 2. Population size of White-winged Wood Ducks recorded in the studbook between 1968 and 1989. 


\section{Genetics}

With the conservative assumptions about parentage (see above) built in to the pedigree all 70 White-winged Wood Ducks were descended from just seven wild individuals or 'founders' (Table 2). We have assumed that they are all unrelated to each other and are not inbred themselves. Levels of relatedness among founder birds may, however, be higher than we assumed as their capture status was unknown. From the gene drop simulation the average heterozygosity retained is 0.81 and the number of unique alleles surviving is estimated to be 5.21 from a starting number of 14 (seven founders $x$ two alleles). The founder genome equivalents score $\left(F_{g c}\right)$ is a measure devised by Lacy (1989), and can be interpreted as the number of unrelated wild caught individuals which would represent the same amount of genetic diversity as is found in the present living population. The founder genome equivalents score of 2.58 found here is very low, partly because of the low founder number (seven) and partly because of the high levels of inbreeding and bottlenecking in the population which have occurred since the importation of the wild individuals.
Genetic variability, measured by the $\mathrm{F}_{\mathrm{gc}}$ score, could be maximised by adjusting to target levels the genetic contribution from each of the founders to the living population. These target levels would equalise the contribution of each founder after allowing for the fact that a proportion of each founder's genes has already been lost (see Lacy 1989). The target values are shown compared with existing values in Figure 3 . If target founder contributions were achieved the $F_{g e}$ score could potentially rise from 2.58 to 5.21 . There is, then, limited scope for improvement in genetic variability by breeding preferentially from the descendants of under-represented founders.

The average inbreeding coefficient has been increasing over the years, but may now be decreasing (Fig. 4). The high level for 1989 is based on only four hatchings and may not be representative. Although there may appear to be a negative relationship between the relatedness of the parents (equivalent to the inbreeding coefficients of the offspring) and the breeding success of their offspring (Table 3) it was not significant (Spearman rank correlation $=0.4248, N=20$ with the average number of offspring that bred per clutch per kinship coefficient; nine coefficients

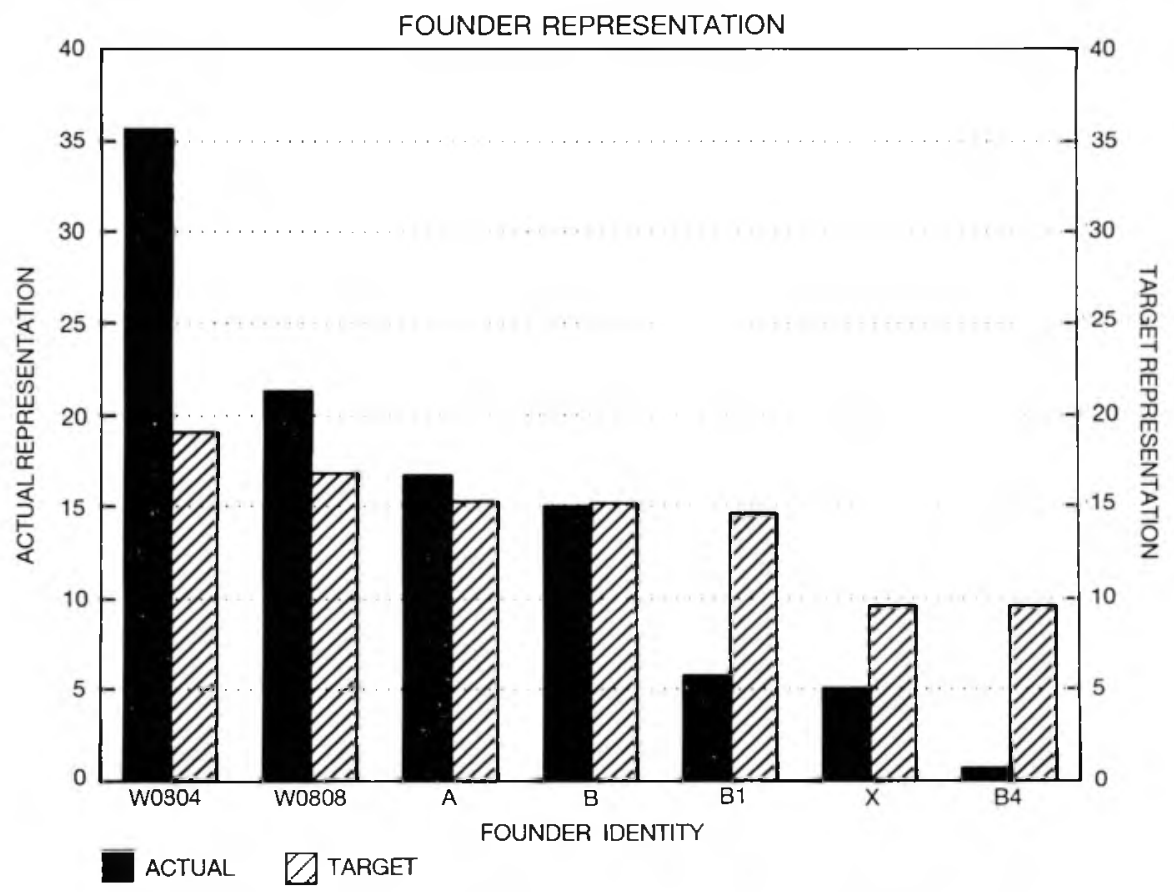

Figure 3. Actual and target genetic representation for the seven founders to the living White-winged Wood Duck population. Founder identities are ring numbers in the studbook except for $A, B$ and $X$ which are wild individuals that were never brought into captivity, but whose offspring were founders to the captive population. A and B were the parents of W0805, W0809 and W0810. X was the mate of B1 and father of S1485. Breeding by descendants of the under-represented founders should be favoured in order to improve overall levels of genetic diversity (see text). 

INBREEDING COEFFICIENTS

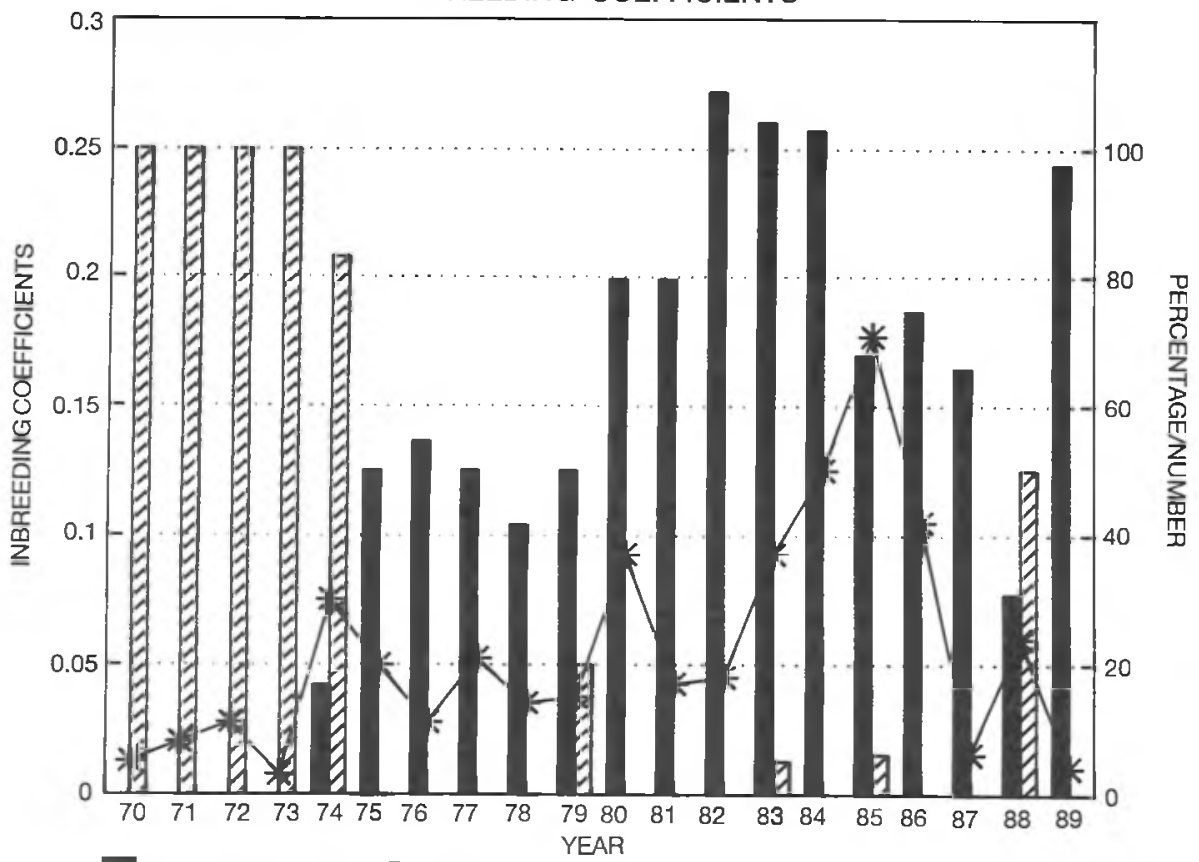

AV. INB. COEFF.

Z\% NOT INBRED

* No. FLEDGED

Figure 4. Changes in inbreeding levels 1969-89. The average inbreeding coefficient of all chicks hatched in each year is shown with the proportion of chicks hatched that were not inbred and the sample size for each year.

were represented by only one pair; six coefficients by two pairs). Nor was the number of offspring which survived to one year significantly related to the kinship coefficient of the parents. Other factors which may also affect offspring survival and breeding success, such as the previous breeding experiences of the parents (Table 3) and the age of either parent were not possible to separate from each other because of the inability to normalize the data distributions.

Three different methods of calculating the genetically effective population size were used. The formula of Hill (1972) gave a value of 6.58, Reed et al. (1986) gave 13.12 which was re- duced to 6.55 when the adjustment for non-Poisson distribution of family sizes (Harris \& Allendorf 1989) was applied, and the direct calculation from the gene drop simulation gave a value of 3.62. The ratio of effective to census population size for this species is therefore between 0.052 and 0.094 . These are very low ratios compared to values of between 0.2 and 0.4 often cited as characteristic of vertebrates (Denniston 1978, Mace 1986).

\section{Demography}

Over the recorded captive history of

Table 3. The relationships between the relatedness of the parents (coefficient of kinship) and their previous breeding experience on reproductive success (Surviving $(S)=$ offspring surviving to one year, Bred $(B)=$ offspring that bred). The 43 unique pairs were comprised of 35 males and 39 females. The term 'clutch' here represents all offspring of a unique pair produced in one year.

\begin{tabular}{|c|c|c|c|c|c|c|c|}
\hline & \multicolumn{3}{|c|}{$\begin{array}{l}\text { Coefficient of kinship } \\
\text { of parents }\end{array}$} & \multicolumn{4}{|c|}{$\begin{array}{l}\text { No. previous clutches } \\
\text { together }\end{array}$} \\
\hline & $0-.099$ & $0.1-.199$ & 0.2- & 0 & 1 & 2 & 3 \\
\hline No. unique pairs & 9 & 16 & 18 & & & & \\
\hline Total no. clutches & 14 & 27 & 28 & 43 & 13 & 8 & 5 \\
\hline Total no. surviving & 77 & 237 & 108 & 234 & 62 & 57 & 48 \\
\hline Total no. bred & 24 & 32 & 12 & 35 & 12 & 8 & 13 \\
\hline Av. no. S/Clutch & 5.5 & 8.0 & 3.9 & 5.4 & 4.8 & 7.1 & 9.6 \\
\hline Av. no. B/Clutch & 1.7 & 1.2 & 0.4 & 0.8 & 0.9 & 1.0 & 2.6 \\
\hline
\end{tabular}


White-winged Wood Ducks, the average generation length has increased slightly as has their life span, average age, and maximum longevity (Table 2). The growth rate of the population, however, was higher in 1980 to 1984 than in the past five years.

Age specific fecundity rates are shown in Figure 5. Both males and females start to reproduce in their second year, but are much more productive in their fifth year. Prior to 1985 , females apparently showed a decline after this peak, but this is due to the population at that time consisting of mostly young birds. No female has been reproductive after ten years of age. Males show a peak at five years and have been recorded breeding at 13 years. In recent years the breeding of older males has become improved, but this probably results from an increased number of older individuals in the population.

Survivorship curves for males and females are shown in Figures $6 \mathrm{a}$ and $6 \mathrm{~b}$ and are expressed as the number of individuals (from an original population of 1000 ) surviving to each age class. The pattern has not changed very much over the years except that older birds have tended to survive better in recent years. There is also a tendency for males to survive better than females over all age classes. Half the females have died by age four, whereas half the males survive to age five.

If demographic statistics for the last five years continue to be characteristic, the female population will continue to increase slowly and will number about 86 by the year 2010 . With a roughly equal sex ratio the total population size should be about 170 individuals.

\section{Calculation of MVP}

Table 4 shows the actual population sizes which would be required to retain $90 \%$ heterozygosity with lambda (annual population growth rate) equal to 1.2 , a generation length of 4.2 years and ten or 20 effective founders. The ratio of effective to census population size and the time period for the programme were allowed to vary in these calculations. It is clear that even the most modest aims require prohibitively large population sizes unless both the effective founder number and the ratio of effective to census population size are increased from their present levels. At least ten, and ideally 20, effective founders are needed, together with an effective to census population size ratio of at least 0.2 , to move the required MVP for 100 years to below 1000 birds.

\section{Discussion}

A first priority should be a thorough investigation of White-winged Wood Duck flocks in the USA and Asia in order to improve the accuracy of both the genetic and demographic analyses which may reveal a more optimistic future for the captive programme. The present census includes only one potentially new founder (if alive) in Asia, but re-analysis of a more complete data set may indicate the existence of other potential founders.

More information is also required to determine the cause of the recent decline in population growth rates. Since 1986 the Slimbridge birds have been managed primarily for the purpose of research into avian TB which has caused $89 \%$ of all deaths in the last ten years (Cromie et al. 1990, Cromie 1991). Frequent handling and group housing for the study have created conditions that were largely not conducive to breeding. As more than a third of all birds alive on 31 December 1989 were housed at Slimbridge, it is likely that this has had a significant effect on population size in recent years.

Clearly, there is a need to curtail the incidence of TB which has been responsible for the deaths of up to $68 \%$ of the Slimbridge birds in any one year (Cromie 1991), and an investiga-

Table 4. Population sizes required to maintain $90 \%$ starting heterozygosity for 100 or 200 years, assuming a generation length of 4.2 years, an annual growth rate (lambda) of 1.2, 10 or 20 effective founders and a ratio of effective population size to census size $(\mathrm{N} / \mathrm{N})$ of 0.1 to 0.5 .

\begin{tabular}{cccccc}
\hline & \multicolumn{5}{c}{ Time period (years) } \\
NתN & $\begin{array}{c}\text { Effective } \\
10\end{array}$ & $\begin{array}{c}100 \\
\text { founders }\end{array}$ & $\begin{array}{c}\text { Effective } \\
10\end{array}$ & $\begin{array}{c}\text { 200 } \\
\text { founders } \\
20\end{array}$ \\
\hline 0.10 & 7580 & 1590 & & 3560 \\
0.20 & 3790 & 795 & 9395 & 1780 \\
0.30 & 2527 & 530 & 6263 & 1187 \\
0.40 & 1895 & 398 & 4698 & 890 \\
0.50 & 1516 & 318 & 3758 & 712 \\
\hline
\end{tabular}



a) MALE AGE - SPECIFIC FECUNDITY

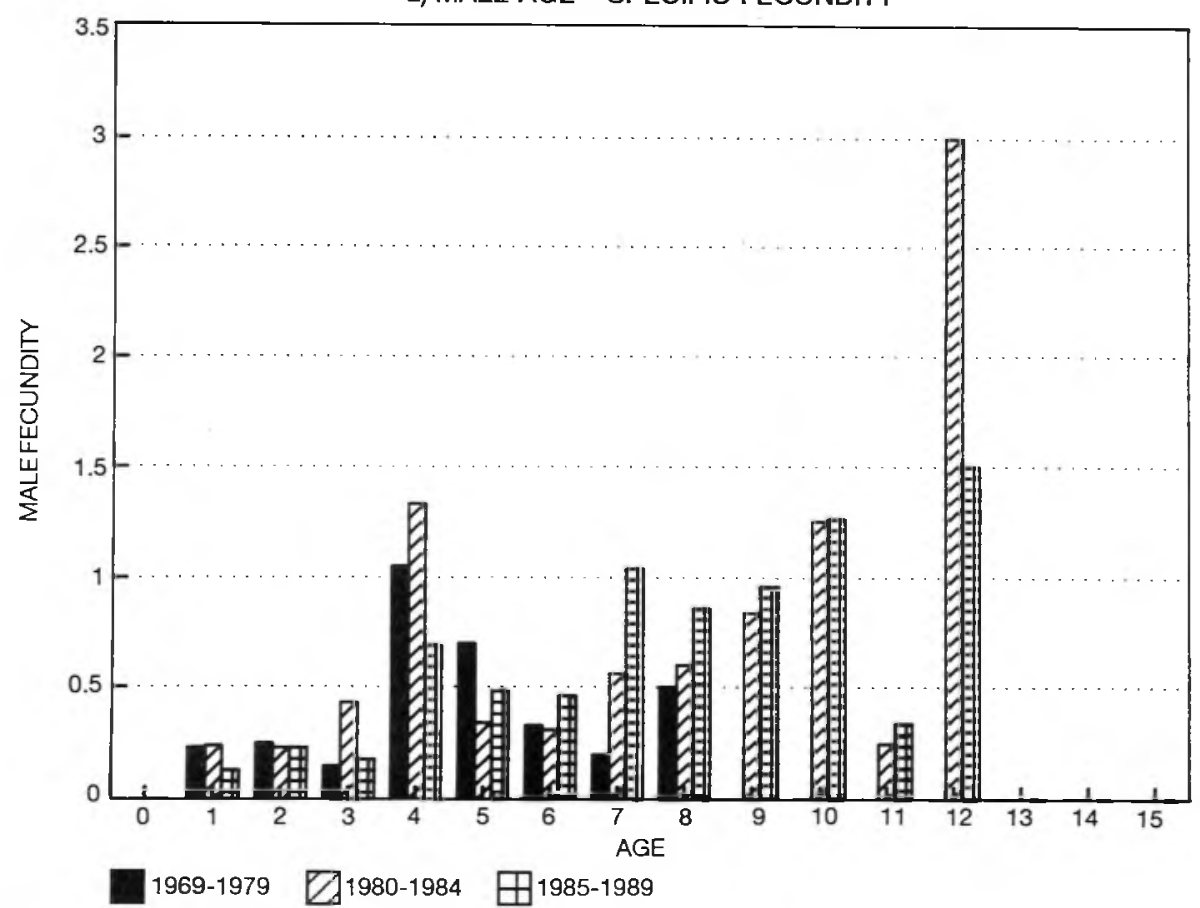

b) FEMALE AGE - SPECIFIC FECUNDITY

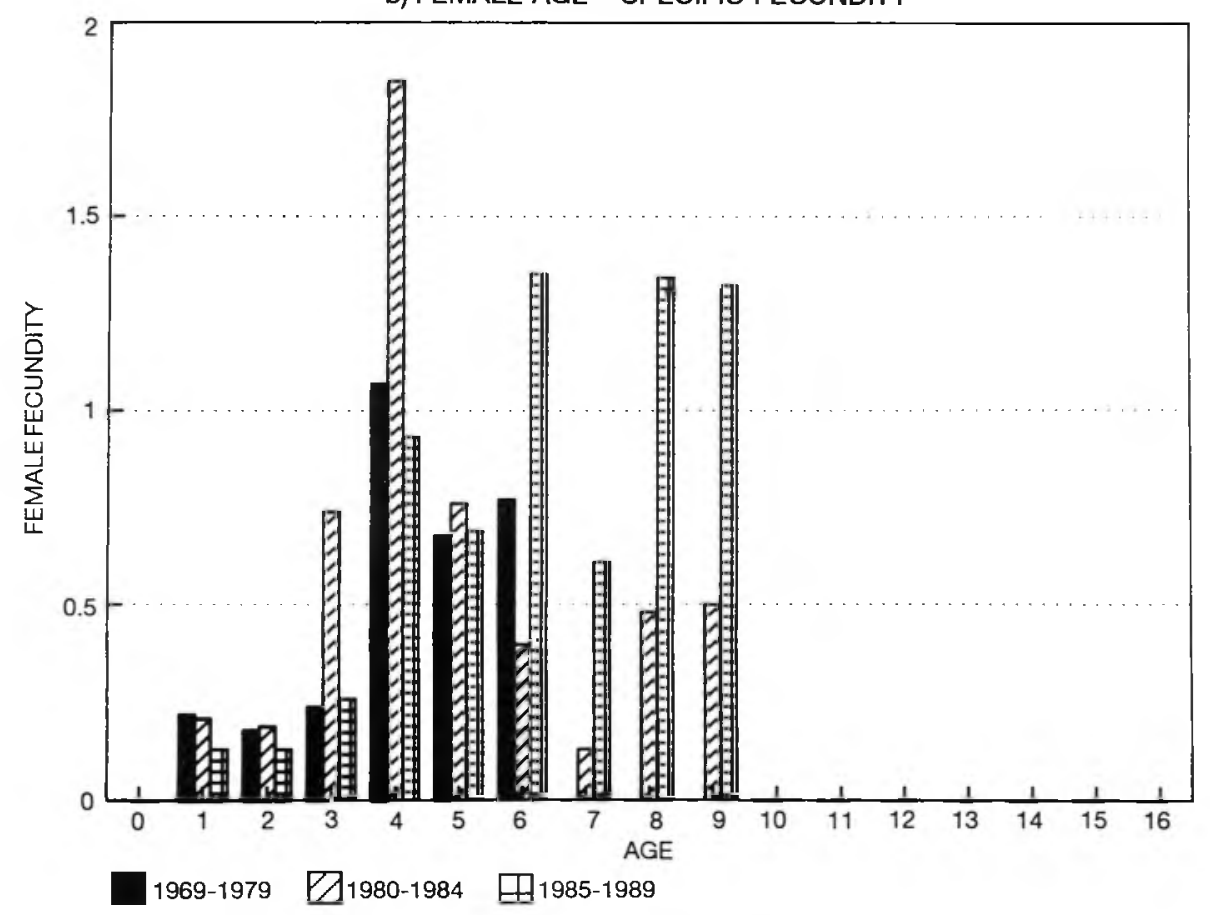

Figure 5. Age-specific fecundity (a) males and (b) females in three different time intervals. 
tion into a workable diagnostic test is being launched at Slimbridge in 1991. As there was no increase in the incidence of TB from 1980 to 1989 , it is difficult to relate this directly to the population decline starting in 1986.

The lack of data since 1986 for 73 of the 83 birds which were assumed dead may also have contributed to the population decline, especially as most of these birds were one or two years old when they were last recorded and the reproductive years are missing.

Deleterious effects of inbreeding have been demonstrated in many other zoo species (Ralls \& Ballou 1983, Laikre \& Ryman 1991), but may not be evident in White-winged Wood Ducks if the founders were taken from small, isolated populations or populations having already gone through a bottleneck. In this case, deleterious alleles may have been eliminated through inbreeding prior to capture. Although it was not possible with this data set, it may be worthwhile determining whether or not there is a relationship between inbreeding and the vulnerability to TB.

The calculations for required MVP above showed that substantial increases in (1) founder number, (2) population size and in (3) effective population size relative to census size are also needed if the captive population is to be valuable in the overall conservation of the species. The present founder number of seven is very small, and would not be sufficient to preserve genetic variability even over the short-term in an ideally managed population. Over the course of the last 20 years the distribution of breeding success in the captive flocks of White-winged Wood Ducks has tended to be highly biased towards just a few highly productive pairs, further reducing the genetically effective founder number. At present, the population is genetically representative of only about three unrelated birds. Changes in founder contributions in the present population, by breeding preferentially from 'under-represented' founders to adjust founder contributions to target levels (see above) can only have a very negligible impact on the founder number and will not be sufficient to increase it to even minimum required levels. At the very least ten, and ideally 20 genetically effective founders are needed if any kind of useful long-term genetic goal is to be achievable. The best way to increase founder number will be to identify unrelated lineages in the captive populations elsewhere in the world, as this will not involve the removal of more wild birds.

Another consideration pointing to the need for more founders is that of rare alleles. Their loss is strongly influenced by both the initial number of founders and their original heterozygosity. Rare alleles, however, have little influence on measures of heterozygosity so their degree of loss remains undetected (Fuerst \& Maruyama 1986). Although White-winged Wood Ducks have a large distribution over a wide range of habitats and thus may exhibit a high level of heterozygosity, if these populations have themselves become separate and small, they too may have already lost a large proportion of their rare alleles. Until more information on the wild populations becomes available, it may be prudent to consider the geographic (or habitat) origins of the founders and, if possible, to vary these so as to sample more of the rare alleles. However, the addition of wild caught birds should be carefully considered if present captive stocks prove inadequate. Managers should also consider the maintainance of two separate captive stocks as the Indonesian population apparently tends toward albinistic plumage (Mackenzie 1990, Green in press). The Slimbridge stock consists of only the darker continental birds. Until a comprehensive genetic investigation is undertaken it may be prudent to consider these populations as separate also because of the disparity between habitats that the ducks utilise (Green, in press).

Even once the founder number is increased changes in breeding management will also be necessary to increase the present very low effective population size. Several different methods were used to calculate the effective size of the population. The lowest estimate was from the pedigree simulation which might be expected to under-estimate slightly because of the very conservative assumptions made about parentage. The various formulae are discussed in detail by Harris \& Allendorf (1989) who show that both the Hill and the modified Reed et al. (1986) methods give good approximations to real values. In the case of this population, however, it seems likely that close inbreeding would be more common than these techniques allow for. It seems unlikely therefore that the effective to census population size ratio in this population was as great as 0.1 , but probably greater than 0.05 . The ratio was particularly low because a very small proportion of pairs bred successfully and because those that did tended to be highly inbred. Even quite modest improvements in the number of breeding pairs within and between years, and the avoidance of close inbreeding should make it possible to increase the effective to census population size ratio to at least 0.2 and probably closer to 0.3 or 0.4 . In managed 
a) MALE SURVIVORSHIP

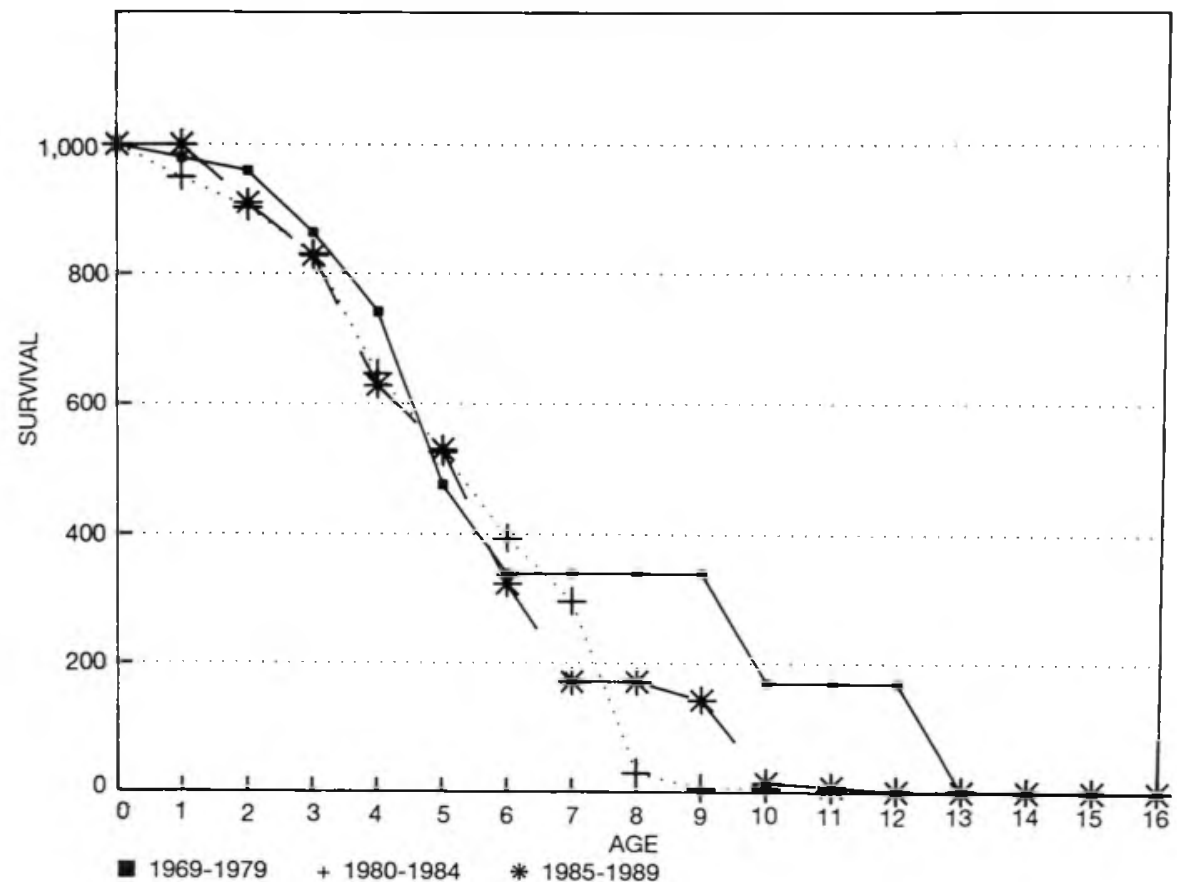

b) FEMALE SURVIVORSHIP

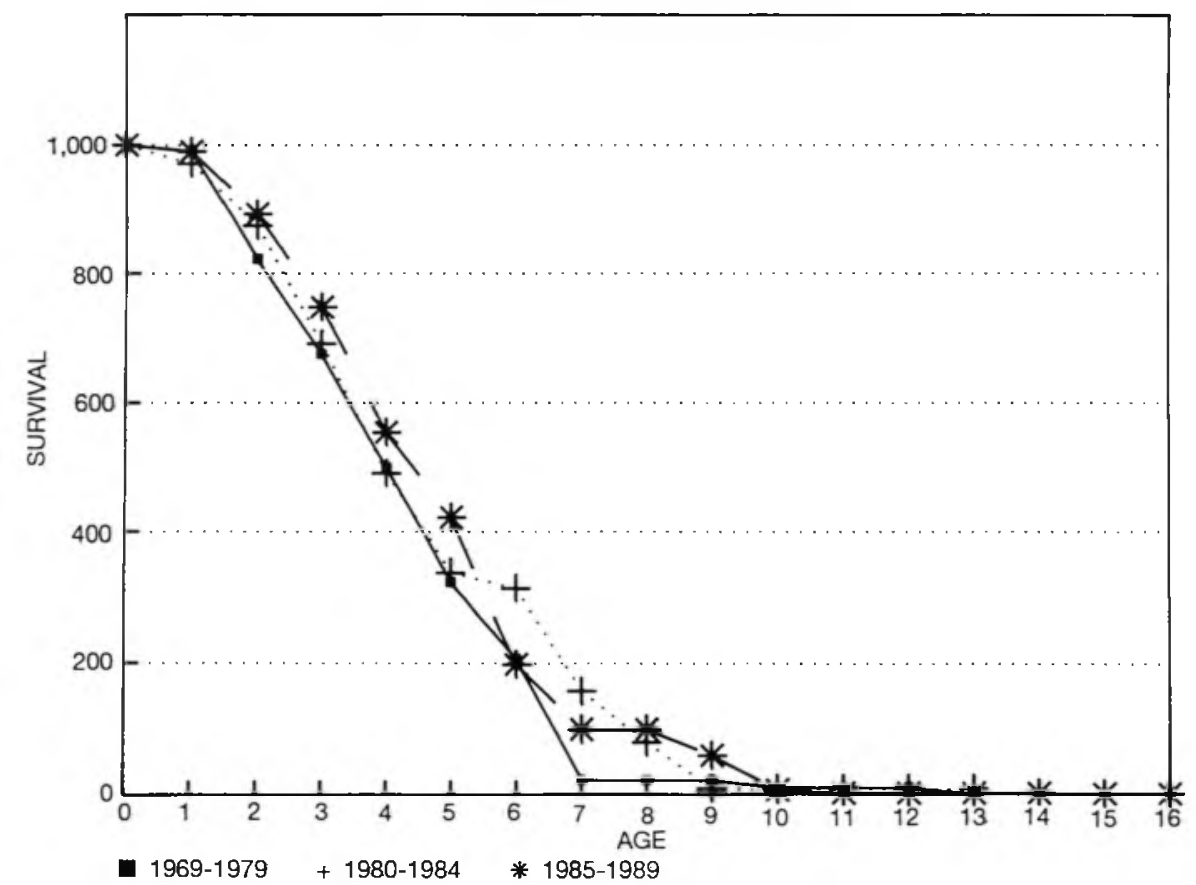

Figure 6. Age-specific survival rates of (a) males and (b) females in three different time periods. 
populations of monogamous species these are quite reasonable levels to expect (Denniston 1978, Mace 1986). With 20 effective founders and an effective to census population size ratio of 0.3 the MVP required to maintain $90 \%$ heterozygosity for 100 years will be 530 birds, a realistic aim for a national or international breeding programme for the species. To realise this aim the Wildfowl \& Wetlands Trust plans to establish a recognised international studbook which can form the basis of a fully coordinated breeding programme.

\section{References}

Baker, E.C.S. 1921. Indian Ducks and their Allies. 2nd Edition. Bombay: Bombay Natural History Society.

Collar, N.J. \& Andrew, P. 1988. Birds to Watch. ICBP Tech. Publ. No. 8.

Cromie, R.L. 1991. Development of an avian tuberculosis vaccine for captive wildfowl. Ph.D Thesis, University of London.

Cromie. R.L., Stanford, J.L., Brown, M.J. \& Price, D.J. 1990. A progress report of the project to develop a vaccine against avian tuberculosis in wildfowl. Wildfowl 40:146-148.

Delacour, J. 1959. The Waterfowl of the World. Vol. 3. Country Life, London.

Denniston, C. 1978. Small population size and genetic diversity: implications for endangered species. In: Endangered birds: management techniques for preserving threatened species. Ed. S.A. Temple. Madison: University of Wisconsin Press.

Foose, T.J. 1983. The relevance of captive propogation to the conservation of genetic diversity. In: Genetics and Conservation. Ed. Schonewald-Cox et al. California: Benjamin Cummings Pub. Co. California.

Foose, T.J. \& Ballou, J. 1988. Management of small populations. International Zoo Yearbook 27:26-41.

Fuerst, P.A. \& Maruyama, T. 1986. Considerations on the conservation of alleles and of genic heterozygosity in small managed populations. Zoo Biology 5:171-179.

Green, A. 1990. Progress in White-winged Wood Duck Cairina scutulata action plan project: a call for information. Wildfowl 41:161-162.

Green, A. In press. The status and conservation of the White-winged Wood Duck Cairina scutulata. IWRB Special Publications.

Harris, R.B. \& Allendorf, F.W. 1989. Genetically effective population size of large mammals: an assessment of estimators. Conservation Biology 3:181-191.

Hill, W.G. 1972. Effective size of populations with overlapping generations. Theoretical Population Biology 3:278-289.

ISIS 1988. SPARKS.

Kear, J. \& Williams, G. 1978. Waterfowl at risk. Wildfowl 29:5-21.

Lacy, R.C. 1989. Analysis of founder representation in pedigrees: founder equivalents and founder genome equivalents. Zoo Biology 8:111-124.

Laikre, L. \& Ryman, N. 1991. Inbri eeding depression in a captive wolf (Canis lupus) population. Cons. Biol. 5:33-40.

Lubbock, M.R. 1975. White-winged Wood Duck at Slimbridge. Avic. Mag. 81:153-154.

Mace, G.M. 1986. Genetic management of small populations. International Zoo Yearbook 24/ 25:167-174.

Mackenzie, M.J.S. 1990. White-winged Wood Duck Cairina scutulata - the question of Indonesian albinism. Wildfowl 41:163-166.

Mackenzie, M.J.S. \& Kear, J. 1976. The White-winged Wood Duck. Wildfowl 27:5-17.

MacLuer, J.W., Vandenburgh, J.L., Read, B. \& Ryder, O.A. 1986. Pedigree analysis by computer simulation. Zoo Biology 5:147-160.

Ralls, K. \& Ballou, J. 1983. Extinction: lessons from zoos. In: Genetics and Conservation. Ed. Schonewald-Cox et al. California: Benjamin Cummings Pub. Co. California.

Reed, J.M., Doerr, P.D. \& Walters, J.R. 1986. Determining minimum viable population sizes for birds and mammals. Wildlife Society Bulletin 14:255-261.

Soule, M., Gilpin, M., Conway, W. \& Foose, T.J. 1986. The millenium ark: how long the voyage, how many staterooms, how many passengers? Zoo Biology 5:101-113.

Cynthia Tomlinson and Georgina M. Mace, Institute of Zoology, Zoological Society of London, Regent's Park, London, NW1 4RY.

Jeffrey M. Black• and Nigel Hewston', The Wildfowl \& Wetlands Trust, Slimbridge, Gloucester, GL2 7BT.

"To whom correspondence should be sent.

${ }^{\mathrm{b}}$ For correspondence about captive breeding programmes for White-winged Wood Duck. 
